\title{
Spatiotemporal variation of Van der Burgh's coefficient in a salt plug estuary
}

\author{
Dinesh Chandra Shaha ${ }^{1,2}$, Yang-Ki Cho ${ }^{2}$, Bong Guk Kim ${ }^{2}$, M. Rafi Afruz Sony ${ }^{1}$, Sampa Rani Kundu ${ }^{3}$, and \\ M. Faruqul Islam 4 \\ ${ }^{1}$ Department of Fisheries Management, Bangabandhu Sheikh Mujibur Rahman Agricultural University, \\ Gazipur 1706, Bangladesh \\ ${ }^{2}$ School of Earth and Environmental Science/Research Institute of Oceanography, Seoul National University, \\ Seoul, Korea \\ ${ }^{3}$ Deparment of Oceanography, Chonnam National University, Gwangju, Korea \\ ${ }^{4}$ Hydrography Division, Mongla Port Authority, Bagherhat, Bangladesh \\ Correspondence to: Yang-Ki Cho (choyk@snu.ac.kr)
}

Received: 11 February 2017 - Discussion started: 21 March 2017

Revised: 28 July 2017 - Accepted: 8 August 2017 - Published: 13 September 2017

\begin{abstract}
Salt water intrusion in estuaries is expected to become a serious global issue due to climate change. Van der Burgh's coefficient, $K$, is a good proxy for describing the relative contribution of tide-driven and gravitational (dischargedriven and density-driven) components of salt transport in estuaries. However, debate continues over the use of the $K$ value for an estuary where $K$ should be a constant, spatially varying, or time-independent factor for different river discharge conditions. In this study, we determined $K$ during spring and neap tides in the dry $\left(<30 \mathrm{~m}^{-3} \mathrm{~s}^{-1}\right)$ and wet $\left(>750 \mathrm{~m}^{-3} \mathrm{~s}^{-1}\right)$ seasons in a salt plug estuary with an exponentially varying width and depth, to examine the relative contributions of tidal versus density-driven salt transport mechanisms. High-resolution salinity data were used to determine $K$. Discharge-driven gravitational circulation ( $K \sim 0.8$ ) was entirely dominant over tidal dispersion during spring and neap tides in the wet season, to the extent that salt transport upstream was effectively reduced, resulting in the estuary remaining in a relatively fresh state. In contrast, $K$ increased gradually seaward $(K \sim 0.74)$ and landward $(K \sim 0.74)$ from the salt plug area $(K \sim 0.65)$ during the dry season, similar to an inverse and positive estuary, respectively. As a result, density-driven inverse gravitational circulation between the salt plug and the sea facilitates inverse estuarine circulation. On the other hand, positive estuarine circulation between the salt plug and the river arose due to density-driven positive gravitational circulation during the
\end{abstract}

dry season, causing the upstream intrusion of high-salinity bottom water. Our results explicitly show that $K$ varies spatially and depends on the river discharge. This result provides a better understanding of the distribution of hydrographic properties.

\section{Introduction}

A quantitative understanding of the characteristics of salinity distribution and transport under various environmental conditions is essential for the interpretation of the physical, chemical, biological, and ecological status of an estuary. Salt water intrusion into tropical estuaries has received substantial attention in recent years due to changes in rainfall frequency and intensity levels. In addition, salt water intrusion can be aggravated by decreasing river discharges that result from barrages being built upstream to provide water for drinking and irrigation (Shaha and Cho, 2016). Changes in river discharge levels alter estuarine circulation, stratification, flushing times, salt water intrusion, as well as the transport of biota and dissolved and particulate materials such as salt, pollutants, nutrients, and organic matter (Azevedo et al., 2010; Lee and An, 2015; Savenije, 2012; Shaha and Cho, 2016; Valle-Levinson, 2010). Therefore, it is particularly important to understand the responses of estuarine salt transport mechanisms to temporal changes in river discharge levels be- 
cause salt water intrusion may lead to shortages of drinking and irrigation water (Khan et al., 2011), decreased rice production (Mirza, 2004), reduced freshwater fish habitat (Dasgupta et al., 2014), and inadequate industrial freshwater supplies (Mirza, 1998).

Estuarine circulation represents the interaction among contributions from gravitational circulation, tidal residual circulation, and circulation driven by tidally asymmetric vertical mixing. In turn, gravitational circulation is driven by river discharge and density gradients (Valle-Levinson, 2011). Gravitational circulation tends to be dominant in many estuaries and can be classified according to the morphology or origin of the basin, its water balance, or the competition between tidal forcing and river discharge (ValleLevinson, 2011). Van der Burgh's coefficient, $K$, is one parameter used to describe the relative weights of both tidal and density-driven horizontal salt transport mechanisms in estuaries (Savenije, 2005; Shaha and Cho, 2011; Van der Burgh, 1972). Tidal mixing and density-driven mixing vary along the axis of an estuary according to the tidal influence and the volume of river discharge. Tide-driven mixing usually dominates downstream; a combination of tidal and gravitational components influences the central regimes, and gravitational mixing tends to dominate upstream (Shaha et al., 2010). Therefore, a constant $K$ value for an estuary, as suggested in earlier work (Gisen, 2015; Savenije, 1993, 2005; Zhang and Savenije, 2017), can not accurately represent the nature of salt transport in estuaries for high and low river discharge conditions. Shaha and Cho (2011), who suggested a modified equation to account for the exponential variation in estuarine widths, examined the spatial variability of $K$ along the axis of a small, narrow estuary with a large salinity gradient of $1.4 \mathrm{psu} \mathrm{km}^{-1}$. In the narrow Sumjin estuary, both the large spatial salinity gradient and exponentially varying width are responsible for spatial variation of $K$ and salinity distribution (Shaha and Cho, 2011).

Nonetheless, debate continues as to whether $K$ should be a constant (Savenije, 2005) or spatially varying (Shaha and Cho, 2011) value for estuaries, and/or whether it can serve as a time-independent factor for varying river discharges (Gisen, 2015) and depends on geometries (Gisen, 2015). $K$ is assumed to be a time-independent parameter, with every estuary having its own characteristic $K$ value (Savenije, 1986, 1993, 2005). In their test of a small, narrow estuary, Shaha and Cho (2011) found that $K$ values not only vary owing to different salt transport mechanisms, but also depend on river discharge levels. In contrast, Gisen (2015) assumed $K$ to be independent of the river discharge level, finding instead that it depends on topography. Conversely, Zhang and Savenije (2017) suggested a constant $K$ value if the depth is constant along the estuary; however, the depth typically varies. For instance, earlier research showed that the depth varied in 15 out of 18 estuaries and was constant in only 3 (Zhang and Savenije, 2017). In the present study, we focused on determining $K$ during spring and neap tides in the dry $\left(<30 \mathrm{~m}^{-3} \mathrm{~s}^{-1}\right)$ and wet $\left(>750 \mathrm{~m}^{-3} \mathrm{~s}^{-1}\right)$ seasons in a salt plug estuary with an exponentially varying width and depth to examine the relative contributions of tidal versus gravitational components of salt transport mechanisms. In addition, whether $K$ functions in an inverse salinity gradient area of a salt plug estuary has, thus far, not been examined. Therefore, we also examined whether $K$ can serve in an inverse salinity gradient of such a salt plug estuary.

The Pasur River estuary (PRE) is the longest (>164 km) estuary in the southwestern part of the Ganges-Brahmaputra Delta in Bangladesh. Salt water intrusion in the PRE has received substantial attention in recent years due to increases in the magnitude and frequency of salt water intrusion upstream as a result of climate change - from which there is a predicted sea-level rise of $30 \mathrm{~cm}$ by the year 2050 (Intergovernmental Panel on Climate Change (IPCC), 2007) - and decreases in river discharge levels resulting from an upstream barrage (Shaha and Cho, 2016). Most previous studies focused primarily on analyzing the relationship between discharge and salinity in the PRE (Mirza, 1998, 2004; Rahman et al., 2000; Uddin and Haque, 2010). A few studies of the hydrology of mangrove ecosystems (Wahid et al., 2007), fish biodiversity (Gain et al., 2008, 2015), surface-water quality (Rahman et al., 2013), and nutrient distributions (Rahaman et al., 2014) have been conducted in the PRE. Recently, a new type of salt plug formation was discovered in the multi-channel PRE. This was found to have been caused by decreasing river discharge levels resulting from an upstream barrage (Shaha and Cho, 2016). However, earlier work typically omitted details of the salt transport mechanisms in the PRE, and these details are necessary for a complete understanding of the hydrodynamics and causes of salt water intrusion upstream. Therefore, in this study, we applied the equation suggested by Shaha and Cho (2011) to determine $K$ during spring and neap tides in the dry and wet seasons. We sought to determine the variations in salt transport mechanisms in the PRE considering its exponentially varying width and depth, and to assess the influence of river discharge levels on $K$.

\section{Material and methods}

\subsection{Study area}

There are three distinct seasons in Bangladesh: a dry summer from March to June; a rainy monsoon season from July to October; and a dry winter from November to February (Rashid, 1991). River discharge is strongly seasonal. During the wet season (monsoon), approximately 80 to $90 \%$ of the annual rainfall occurs. Maximum discharge occurs between July and October (wet season). In contrast, river discharge is negligible from November to June (dry season).

The Pasur River is the most commercially important river that experiences upstream salt water intrusion in the southwestern coastal zone of Bangladesh (Fig. 1a). The Pasur 
River bifurcates into two distributaries, the Shibsa River and the Pasur River, at Akram Point before entering the Bay of Bengal (Fig. 1b). Approximately $68 \mathrm{~km}$ upstream from Akram Point, the Chunkhuri Channel connects the Pasur River to the Shibsa River at Chalna. The interconnecting channel contributes to complex water circulation between the Pasur and Shibsa estuarine systems (Shaha and Cho, 2016). There is no direct link between the Shibsa River upstream and the major freshwater source, the Ganges River. Therefore, high salinization occurs in the Shibsa estuary relative to the PRE in the dry season owing to the lack of freshwater discharge and precipitation (Shaha and Cho, 2016). On the other hand, the Pasur River is directly connected to the main freshwater source of the Ganges through the Gorai-MadhumatiNabaganga-Rupsha-Pasur (GMNRP) river system (Fig. 1a). The Ganges, which originates in the Himalayas and is the third largest river (in terms of discharge) in the world, was unregulated prior to the construction of the Farakka Barrage in India in 1975. This diversion diminished the average dry season flow in the Ganges from $3114 \mathrm{~m}^{3} \mathrm{~s}^{-1}$ during the pre-Farakka period to $2010 \mathrm{~m}^{3} \mathrm{~s}^{-1}$ in the post-Farakka period (Islam and Gnauck, 2011; Mirza, 2004). As a result, the dry-season discharge in the Gorai River, the major distributary of the Ganges, was reduced from a pre-Farakka mean flow of $190 \mathrm{~m}^{3} \mathrm{~s}^{-1}$ in 1973 (Islam and Gnauck, 2011; Mirza, 2004) to post-Farakka mean flows of $51 \mathrm{~m}^{3} \mathrm{~s}^{-1}$ in 1977 and $10 \mathrm{~m}^{3} \mathrm{~s}^{-1}$ in 2008 (Islam and Gnauck, 2011). Consequently, salt water intrusion has extended as far as $\sim 164 \mathrm{~km}$ (29 March 2014) from the estuarine mouth (at Hiron Point) to a head at Lohagara (Narail District), during the spring tide in the dry season (Shaha and Cho, 2016).

\subsection{Data}

The bathymetric chart of the PRE from Harbaria to Chalna used in this study was collected from the Mongla Port Authority. The cross-sectional depths, areas, and widths at different sampling stations within the study area are shown in Fig. 2. In addition, river discharge data from January to December of 2014 were collected from a non-tidal discharge station on the Gorai River, the main upstream freshwater source of the PRE. Tidal water level data for Mongla Port and Hiron Point were obtained from the Mongla Port Authority (Fig. 1b). The tidal range varied from 1.6 to $3.0 \mathrm{~m}$ at Hiron Point and from 2.2 to $4.0 \mathrm{~m}$ at Mongla Port during the neap and spring tides, respectively (BIWTA, 2014). The tidal range is higher in Mongla Port than at Hiron Point.

Nine longitudinal depth profiles of salinity were taken using a conductivity-temperature-depth (CTD) profiler (model: In-situ Aqua TROLL 200, In-situ Inc., Fort Collins, Colorado, USA) along the main axis of the Pasur River from Harbaria to Rupsha Bridge (>60 km). Speed boats or mechanized boats are not allowed to operate southward from Harbaria to the estuary mouth due to the strong tidal influence. Longitudinal transects were taken at high water levels dur-
Table 1. Sampling scheme.

\begin{tabular}{lllr}
\hline Seasons & Tide & $\begin{array}{l}\text { Longitudinal conductivity- } \\
\text { temperature-depth transects }\end{array}$ & $\begin{array}{r}\text { River discharge } \\
\left(\mathrm{m}^{3} \mathrm{~s}^{-1}\right)\end{array}$ \\
\hline \multirow{2}{*}{ Dry } & Spring & $\begin{array}{l}\text { 26 December, 29 March, } \\
\text { 29 April, and 13 June 2014 }\end{array}$ & 28.7 \\
& Neap & 24 February and 09 May 2014 & 9.2 \\
\hline \multirow{2}{*}{ Wet } & Spring & 12 July and 24 October 2014 & 803.2 \\
& Neap & 22 August 2014 & 1606.5 \\
\hline
\end{tabular}

ing both neap and spring tides in the wet and dry seasons from February to December of 2014 (Table 1). The use of a global positioning system (GPS) ensured that precise data were obtained at the sampling stations. The nominal distance between stations was approximately $3 \mathrm{~km}$ along the estuary.

\subsection{Methods}

A one-dimensional salinity model is used to predict the salinity in estuaries (Savenije, 2012). Under a steady-state condition, the salt balance equation (Savenije, 2012) can be written as follows:

$S(x)-S_{\mathrm{f}}=\frac{A(x)}{Q} D(x) \frac{\partial S}{\partial x}$,

where $D(x)$ is the longitudinal dispersion coefficient, $S_{\mathrm{f}}$ is the freshwater salinity (usually close to zero), $Q$ is the freshwater discharge, $S(x)$ is the salinity along the estuary at the high water slack, and $A(x)$ is the cross-sectional area. The flow is positive in the upstream direction. By combining the salt balance equation with the Van der Burgh equation, the longitudinal variation of the effective dispersion is given as follows (Savenije, 2005):

$$
\frac{\partial[D(x)]}{\partial x}=K(x) \frac{Q}{A(x)},
$$

where $K(x)$ is the dimensionless Van der Burgh coefficient. The effective dispersion decreases upstream, showing a direct proportion against the velocity $(Q / A=U)$ of the freshwater discharge (Savenije, 2005; Van der Burgh, 1972).

Van der Burgh's method, related to a decrease in the effective dispersion in the upstream direction, is similar to a number of methods developed by other scientists (Hansen and Rattray, 1965; Ippen and Harleman, 1961; Stigter and Siemons, 1967). Among these methods, the theory of Hansen and Rattray (1965) is most similar to Van der Burgh's method. Hansen and Rattray (1965) limited their theory to the central zone of a narrow estuary with a constant cross section, presuming that the salinity in the central zone would decrease linearly upstream. Based on these strong assumptions, the tide-driven horizontal dispersion $D_{\mathrm{t}}$ is given as follows (Savenije, 2005):

$$
\frac{\partial D_{\mathrm{t}}(x)}{\partial x}=\frac{Q}{A(x)} \text {. }
$$




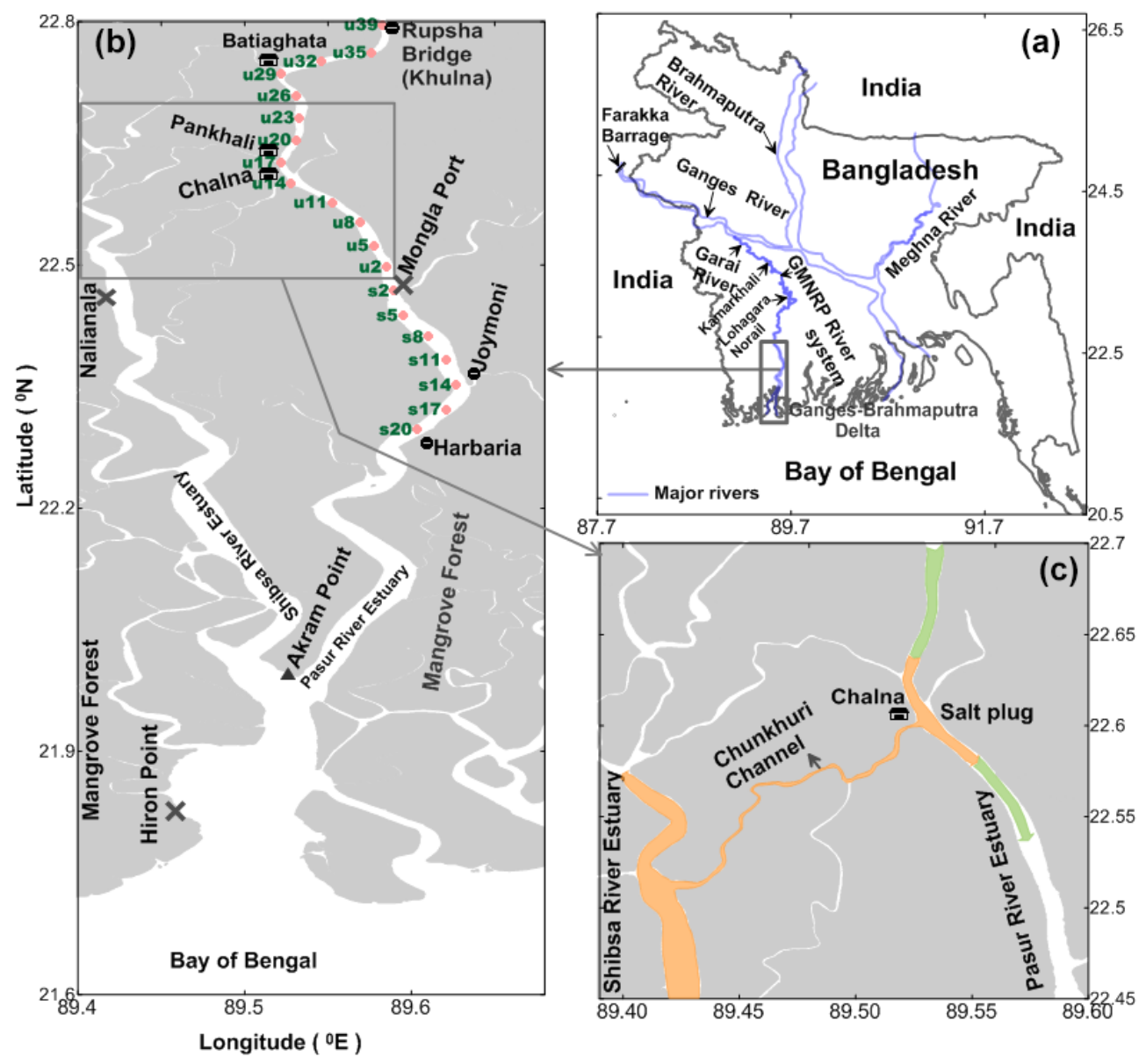

Figure 1. (a) Map of the complex topographical features of the multi-channel Pasur River-Shibsa River estuarine system in the southwestern coastal zone of Bangladesh. (b) Conductivity-temperature-depth (CTD) recorder stations are shown as pink solid circles in the Pasur River. The cross symbols denote the locations of the tidal stations at Hiron Point and Mongla Port. (c) The export of salt water from the Shibsa River estuary to the Pasur River estuary through the Chunkhuri Channel, creating a salt plug. The map was generated using Golden Software Surfer 9.0 (www.goldensoftware.com).

The proportion of the tide-driven dispersion $D_{\mathrm{t}}$ to the total dispersion $D\left(=S U_{f}=S Q / A\right)$ is termed the estuarine parameter, $v$ (Savenije, 2005). The estuarine parameter can be used to characterize the nature of salt transport in estuaries. The contribution by the diffusive portion vs. the advective portion of the total salt flux into the estuary can be given as a function of $x$ :

$v(x)=\frac{D_{\mathrm{t}}(x)}{D(x)}=\frac{D(x) A(x)}{S Q} \frac{\partial S}{\partial x}$.

$D(x)=(Q S(x) / A(x)) /(\partial S / \partial x)$ is applicable to wellmixed estuaries, but strictly inapplicable to stratified conditions (Dyer, 1997). The parameter $v$ can fluctuate between 0 and 1 (Valle-Levinson, 2010). Shaha and Cho (2011) found that $v$ decreased from almost unity near the mouth to zero at the end of the salt intrusion curve, indicating a transition from tide-driven to salinity-driven mixing. Shaha and Cho (2011) investigated the variability of $v$ along the axis of the Sumjin River estuary. In the present study, $v(x)$ was cal- culated using Eq. (4). Equations (3) and (4) can be combined as follows:

$\frac{\partial[D(x)]}{\partial x}=\left\{\frac{1}{v(x)}-\frac{D(x) A(x)}{v(x) Q} \frac{\partial[v(x)]}{\partial x}\right\} \frac{Q}{A(x)}$.

Shaha and Cho (2011) showed the relationship between $K(x)$ and $v(x)$ with Eqs. (2) and (5) as follows:

$K(x)=\frac{1}{v(x)}\left\{1-\frac{D(x) A(x)}{Q} \frac{\partial[v(x)]}{\partial x}\right\}$.

The values of $K$ calculated using Eq. (6) exceed the recommended limit of 1 (Shaha and Cho, 2011).

To limit the feasible range of $0<K<1$ in an estuary with an exponentially varying width, an exponential function was considered with the proportion of tidal dispersion to the total dispersion, $\exp \left(D_{\mathrm{t}} / D\right)$, following the theory of McCarthy (1993). Shaha and Cho (2011) proposed a spatially varying $K$ value for an exponential shaped estuary, as fol- 

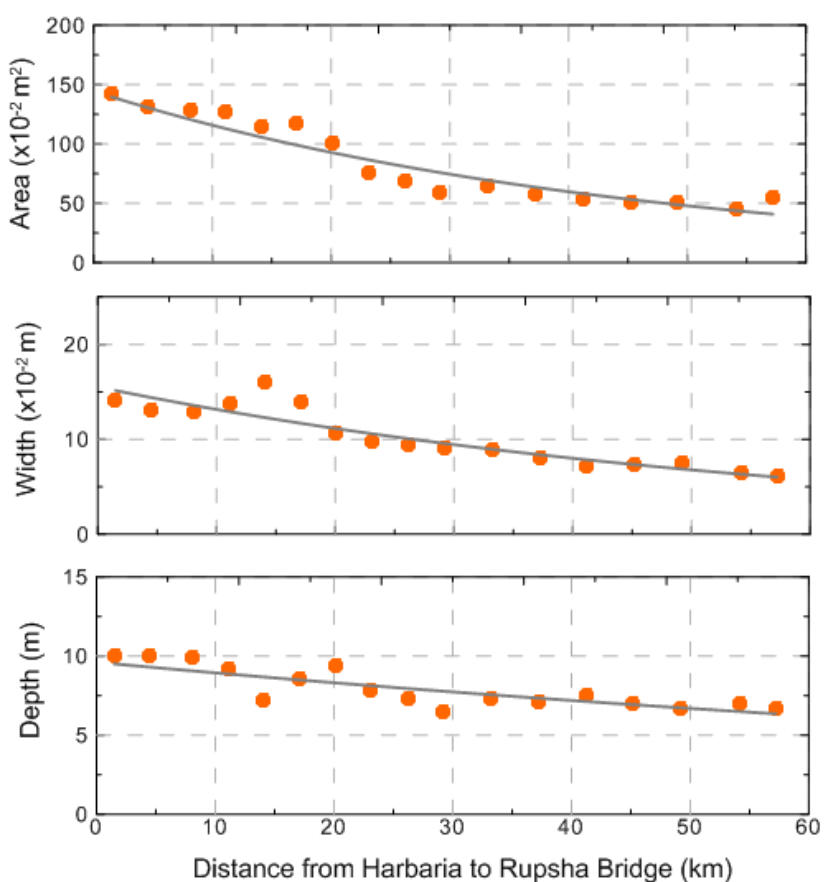

Figure 2. Cross-sectional area, width, and depth of all conductivitytemperature-depth stations in the Pasur River estuary.

lows:

$K(x)=\frac{1}{\exp (v(x))}\left\{1-\frac{D(x) A(x)}{Q} \frac{\partial[v(x)]}{\partial x}\right\}$.

Equation (7) limits the feasible range of $K$, as suggested by several researchers (Eaton, 2007; Savenije, 2005). In addition, $K$ also describes the spatial variation of the tidal- and density-driven mixing of salt transport in the small, narrow estuary (Shaha and Cho, 2011). The $K$ value was scaled based on the $v$ value, and ranges from 0 to 1 (Shaha and Cho, 2011). If $K<0.3$, the total salt transport is driven by diffusive processes (e.g., tidal mixing), as in unidirectional net flows. If $K>0.8$ (or thereabouts), up-estuary salt transport is controlled by advection (i.e., by gravitational circulation). If $0.51<K<0.66$, the dispersion is proportional to the salinity gradient, meaning it is driven by the longitudinal density gradient (Zhang and Savenije, 2017).

\section{Results and discussion}

\subsection{Longitudinal salinity distribution}

Longitudinal sections of vertical salinity were taken during spring and neap tides in the dry and wet seasons along the main axis of the PRE from Harbaria to Rupsha Bridge (Fig. 3). A salt plug formed near Chalna in the PRE, $68 \mathrm{~km}$ upstream from the estuary mouth (Akram Point), owing to export of salt water from the Shibsa River estuary through the Chunkhuri Channel during the dry season (Fig. 3a).
This salt plug, a region of maximum salinity, separates a zone of positive gravitational circulation near the river/estuary area and a zone of inverse gravitational circulation between the salt plug and the coastal ocean (ValleLevinson, 2010). As a result, the salinity declined gradually landward (from Chalna to Rupsha Bridge) and seaward (from Chalna to Harbaria) from the salt plug area, similar to a positive estuary and an inverse estuary, respectively (Shaha and Cho, 2016; Valle-Levinson, 2010; Wolanski, 1986). The salt plug existed from December to June in the PRE, and isolated the upper reaches of the estuary from the coastal water. In contrast, during the wet season, the salt plug advected to the Bay of Bengal and created a typical estuarine condition in which salinity decreased with increase in the distance upstream, moving away from the mouth (Fig. 3b).

The depth-averaged salinity range was $6-17$ in the dry season (Fig. 4). Minimum salinity (6) was found in February, whereas maximum salinity (17) was found in June (Shaha and Cho, 2016). A salt plug started to develop during the period of transition to the dry winter season (December and February). The relative water level variation between the SRE and the PRE during the dry season exerted hydrostatic pressure towards the PRE from the SRE, and facilitated the export of salt water from the SRE to the PRE through the Chunkhuri Channel. This created a salt plug that persisted for several months (December-June). Therefore, the error bar was higher during the dry season than the wet season. In contrast, the salt plug disappeared in the wet season, and allowed development of a typical estuarine system. As a result, the error bar becomes small during the wet season (Fig. 4a). The depth-averaged salinity varied by up to $\sim 4$ psu between spring and neap tides in the dry season (Fig. 4a-b). However, spring-neap variation in the depth-averaged salinity was less than 1.5 psu in the wet season (Fig. 4c). The salinity was lower during neap tides than during spring tides in the wet season, most likely due to higher river-discharge levels. Moreover, strong tidal currents during spring tides tend to suppress gravitational circulation (Geyer, 1993; Savenije, 2005) and thus increase salinity locally.

\subsection{Spatial variation of Van der Burgh's coefficient during the wet season}

Van der Burgh's coefficient characterizes estuarine salt flux mechanisms, which include both tide-driven and gravitational circulation (Savenije, 2006). Gravitational circulation is driven by river discharge and density gradients (ValleLevinson, 2011). Hereafter, we will use the terms densitydriven and discharge-driven gravitational circulation. If the mixing is mostly of the density-driven type, the dispersion should then be proportional to the salinity gradient (Savenije, 2005; Zhang and Savenije, 2017). By contrast, if the mixing is mostly the tide-driven form, then the dispersion is essentially constant. In reality, there is a combination of both mechanisms, whereby tidal mixing is prominent near 
(a) Dry season

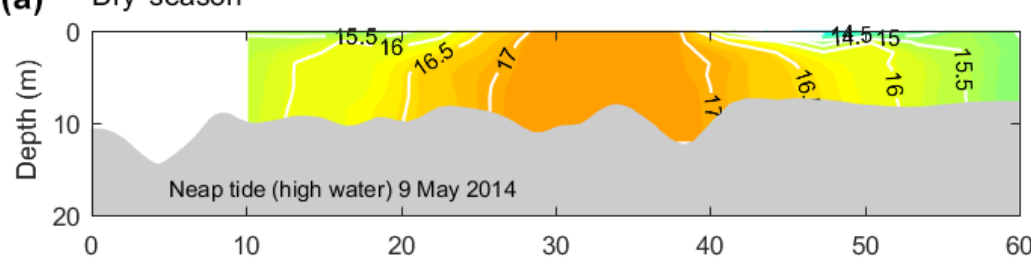

(b) Wet season

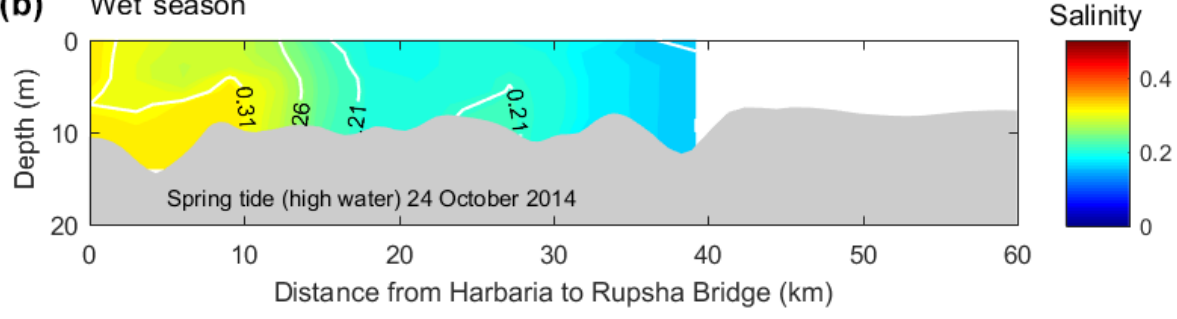

Figure 3. (a) Vertical salinity sections obtained along the main axis of the Pasur River estuary during the dry season. A salt plug developed near Chalna, $34 \mathrm{~km}$ upstream of Harbaria. (b) Vertical salinity sections obtained along the main axis of the Pasur River estuary during the wet season. The salt plug disappeared and a typical estuarine system developed.
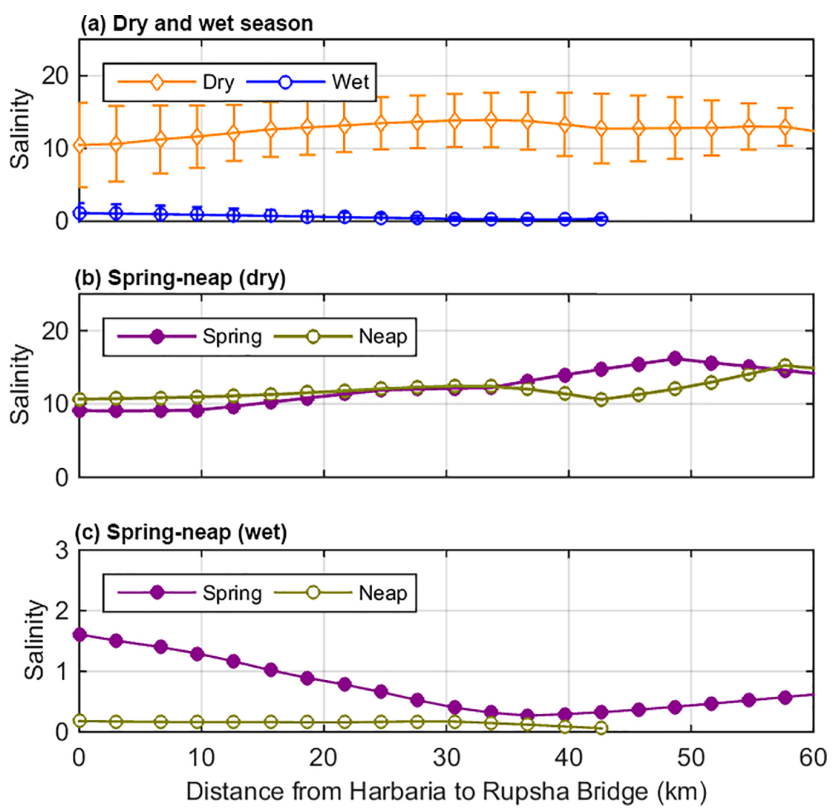

Figure 4. Depth-averaged salinity distribution at high water during neap and spring tides in the Pasur River estuary in the wet and dry seasons.

the mouth of the estuary and gravitational mixing is influential further upstream, where the salinity gradient is steep (Savenije, 2005).

Van der Burgh's coefficient was calculated using Eq. (7) along the length of the PRE, from Harbaria to Rupsha Bridge, using the depth-averaged salinity and the available bathymetric information. Figure 5a depicts the spatial variation of Van der Burgh's coefficient from Harbaria to Rupsha
Bridge in the dry and wet seasons. Discharge-driven gravitational circulation was more influential than tidal dispersion during the wet season and reduced the transport of salt upstream. Upstream (over $10 \mathrm{~km}$ from Harbaria, where $K>0.8$ ), discharge-driven gravitational circulation greatly weakened salt transport due to high river discharge levels $\left(>750 \mathrm{~m}^{3} \mathrm{~s}^{-1}\right)$. The spatial variation of $K$ between spring and neap tide in the wet season was smaller than that in the dry season (Fig. 5b-c).

Additionally, this result shows the effects of the basin's morphology (here, the estuarine length) on salt transport during the wet season. In the PRE (a long estuary), dischargedriven gravitational circulation lessened salt transport substantially in the central regimes, whereas the combined influence of tide-driven and gravitational circulation was found to determine salt transport in the central regimes of a small estuary due to the intense tidal influence (Shaha and Cho, 2011).

\subsection{Spatial variation of Van der Burgh's coefficient during the dry season}

Salt transport mechanisms did not vary significantly between spring and neap tides (Fig. 5b) during the dry season, when the river discharge was low $\left(<30 \mathrm{~m}^{3} \mathrm{~s}^{-1}\right)$. During the dry season, the spatial variation of $K$ indicated a gradual rise in $K$ values seaward from the salt plug (from Chalna to Harbaria, Fig. 5), similar to an inverse estuary. The $K$ value of $\sim 0.65$ near Chalna suggests density-driven inverse gravitational circulation between Chalna and Harbaria because the $K$ value was reduced to 0.65 from 0.74 (Figs. 5-6). This inverse gravitational circulation results from the adjustment of the density gradient under the influence of gravity. The 
(a) Dry and wet season

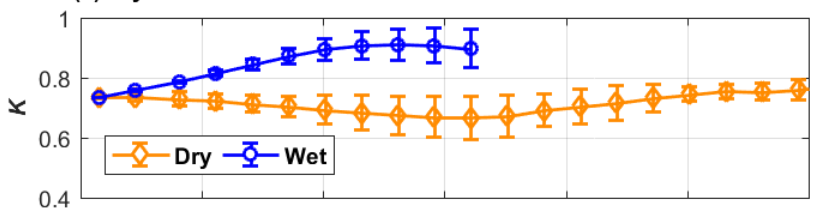

(b) Spring-neap (dry)

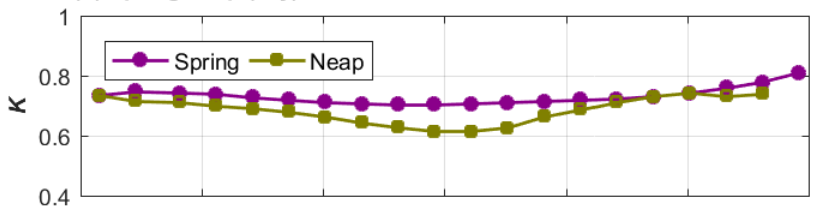

(c) Spring-neap (wet)

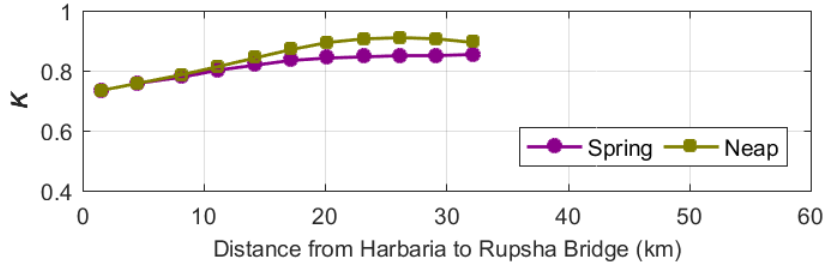

Figure 5. Spatial variation of Van der Burgh's coefficient $(K)$ along the Pasur River estuary. If $K<0.3$, up-estuary salt transport is entirely dominated by tide-driven mixing. If $K>0.8$, up-estuary salt transport is almost entirely dominated by gravitational circulation. If $0.51<K<0.66$, the dispersion is proportional to the longitudinal density gradient.

pressure gradient is affected by the density difference between riverine and oceanic waters (Valle-Levinson, 2011). Zhang and Savenije (2017) reported that dispersion is proportional to the density gradient when $0.51<K<0.66$. Therefore, the gravitational flow produced by the density difference between Chalna and Harbaria (Fig. 6) advances towards the ocean (Harbaria) from the salt plug area (Chalna) during the dry season. As a result, the density-driven gravitational circulation facilitated the import of relatively light seawater moving on the surface toward the salt plug area and the export of the relatively heavy, high-salinity water of the salt plug area flowing near the bottom toward the ocean (Fig. 6). The density-driven flow reversed direction with depth in the salt plug area; thus, the salt plug created a zone of inverse gravitational circulation between it and the coastal ocean.

In addition, during the dry season, the spatial variation of $K$ demonstrated a gradual increase in $K$ landward from the salt plug area (from Chalna to Rupsha Bridge, Figs. 5-6), similar to a positive estuary. The $K$ value of approximately 0.65 around Chalna indicates the control of density-driven positive gravitational circulation for up-estuary salt transport. Zhang and Savenije (2017) found that dispersion was driven by the longitudinal salinity gradient if $K$ ranged from 0.51 to 0.66 . The vertical profiles of salinity clearly indicated that the longitudinal density gradient drove a net volume near-bottom inflow to the Rupsha Bridge from Chalna and a stronger surface outflow to Chalna from the Rupsha
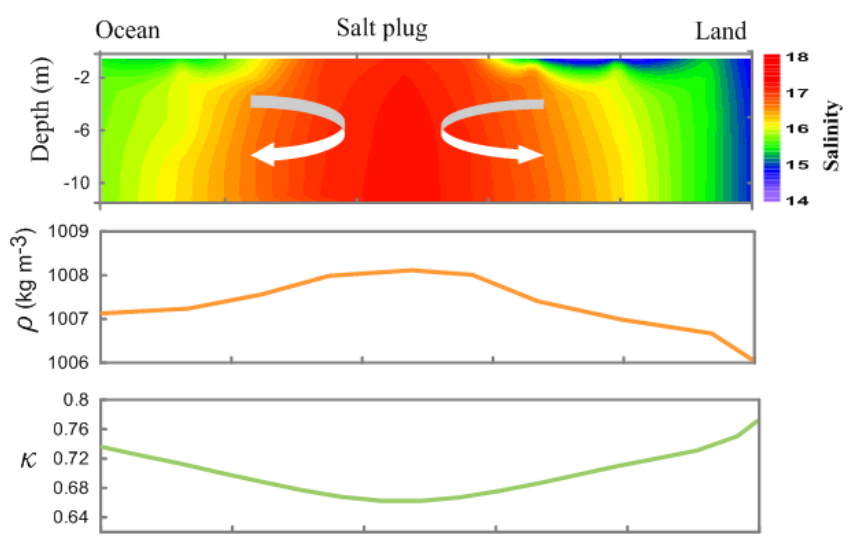

Figure 6. Conceptual diagram of an idealized baroclinic flow in a salt plug. During the dry season when a salt plug is formed, a longitudinal density gradient produces a zone of inverse gravitational circulation between the salt plug and the coastal ocean, and a zone of positive gravitational circulation near the river area. Van der Burgh's coefficient $(K)$ indicates a gradual increase seaward and landward from the center of the salt plug, similar to inverse and positive estuaries, respectively. This shows that $K$ works in the opposite direction, when gravitational circulation is reversed.

Bridge (Fig. 6). This circulation was induced by the volume of freshwater added to the PRE from upstream. Riverine waters, which are less dense than oceanic waters, are forced to flow seaward (Valle-Levinson, 2011). Because the water that flows from the Shibsa River estuary to Chalna through the Chunkhuri Channel is denser than the water moving from upstream of the PRE, the water level at the Ruphsha Bridge is slightly higher than the mean water level. The resultant hydrostatic pressure near the water surface at the Rupsha Bridge is directed towards Chalna. Thus, a strong counteraction between discharge-driven and density-driven gravitational circulation causes landward intrusion of salt water from the salt plug. During the dry season (due to the negligible river discharge), density-driven circulation was induced by the tide; consequently, salt water intrusion extended as far as $\sim 96 \mathrm{~km}$ upstream from Chalna (Shaha and Cho, 2016). As a result, all materials introduced into the estuary by river-side industries can advance upstream with the salt water during the dry season, potentially creating water quality problems (Samad et al., 2015; Shaha and Cho, 2016). The circulation landward of the salt plug resembled that of a typical estuary during the dry season.

\subsection{Relationship between river discharge and Van der Burgh's coefficient $(K)$}

$K$ values were plotted against river discharge to examine the influence of freshwater discharge on the spatial variation in $K$ (Fig. 7). The $K$ values were nearly constant for all levels of freshwater discharge near Harbaria (SEG1 $\sim 3$ ). On the other hand, $K$ depended on the freshwater discharge 


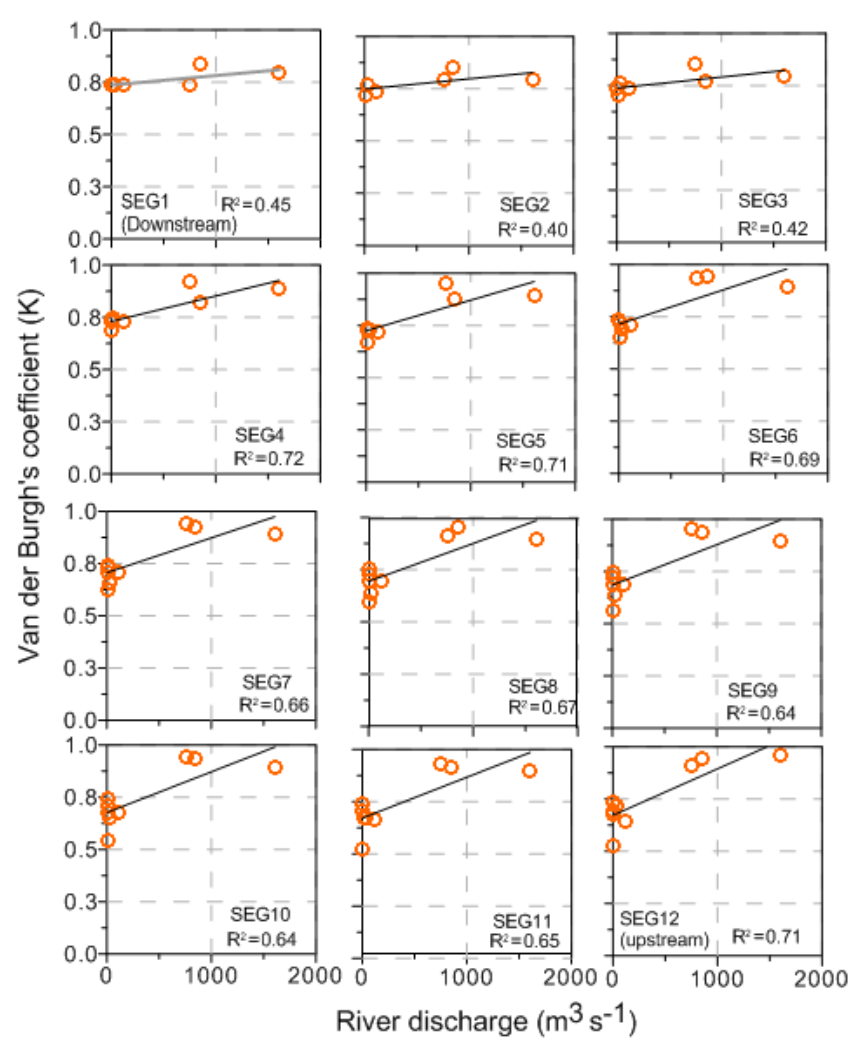

Figure 7. Plots of Van der Burgh's coefficient $(K)$ against river discharge for different segments of the Pasur River estuary.

upstream (SEG4 12), with the coefficient of determination $\left(\mathrm{R}^{2}\right)$ ranging from 0.40 to 0.72 . Although in previous studies (Gisen, 2015; Savenije, 1993, 2005; Shaha and Cho, 2016) it was reported that $K$ is a time-independent parameter, this study revealed that $K$ is not only a time-dependent value (Fig. 7), but also clearly shows inverse and positive gravitational circulation from the salt plug (Fig. 6). Thus, dischargedriven and density-driven salt flux differed with changing river discharge levels.

$K$ values calculated with Eq. (6) for different levels of river discharge did not lie within the feasible range of $0<K<1$, as shown in Fig. 8. However, the spatially different $K$ values determined from Eq. (7) were within the recommended range. Moreover, these values described the spatial variation of the salt transport mechanisms in the PRE during the dry and wet seasons. Salt transport was influenced by density-driven mixing mechanisms in the central regimes of the large PRE, where salt plug occurred during the dry season. This density-driven mechanism clearly showed inverse and positive gravitational circulation seaward and landward, respectively, from the salt plug area.

The river discharge in the Schelde estuary is large compared to the tidal flow (Savenije, 2005). In the upper reaches of the Schelde estuary, river discharge is largely responsible for the considerable tidal damping that occurs. There-

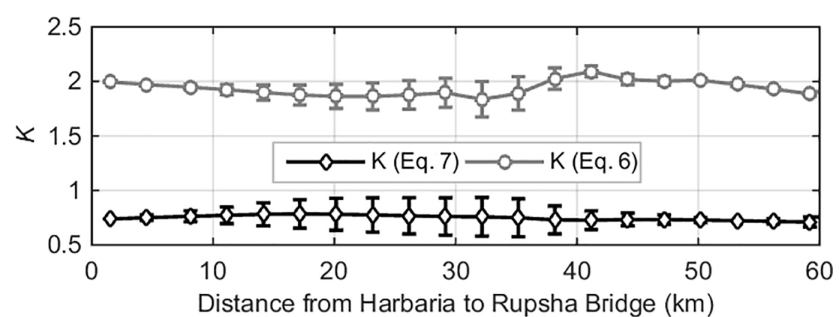

Figure 8. Spatial variation of Van der Burgh's coefficient $(K)$ as calculated using Eqs. (6) and (7).

fore, density-driven mixing is prominent upstream from 60 to $100 \mathrm{~km}$ in the Schelde estuary (Savenije, 2005). By contrast, tidal mixing mainly controls the salt transport landward, up to $60 \mathrm{~km}$ from the mouth of the Schelde estuary (Savenije, 2005). Therefore, a single value of $K(0.25)$ cannot represent the spatial variation of both the tide-driven and densitydriven mixing mechanisms in the Schelde estuary (Savenije, 2005). Therefore, one would expect a lower value of $K$ : between 0.51 and 0.66 (Zhang and Savenije, 2017) for the salt plug area to describe the density-driven salt transport mechanisms obtainable from Eq. (7). Thus, the $K$ values of Eq. (7) described the density-driven salt transport mechanisms in the salt plug area during the dry season. In addition, during the wet season, gravitational circulation almost entirely dominated tidal dispersion in the central regimes of the PRE, and efficiently lessened salt transport upstream due to the high river discharge level. Therefore, it is clear that spatially varying time-dependent $K$ values are indeed required to explain the nature of the spatially varying salt transport mechanisms in a salt plug estuary with a varying geometry.

\section{Conclusions}

We determined the spatially varying Van der Burgh's coefficient along the axis of the PRE using high-resolution salinity data to characterize salt flux mechanisms in the dry and wet seasons. In the wet season, discharge-driven gravitational circulation was almost entirely dominant over tidal dispersion, effectively diminishing salt transport upstream during spring and neap tides due to the high river discharge level $\left(>750 \mathrm{~m}^{3} \mathrm{~s}^{-1}\right)$. On the other hand, during the dry season, when the salt plug formed due to decreasing river discharge upstream, $K$ values were reduced to those of the salt plug area $(\sim 0.65)$ from the periphery $(\sim 0.74)$, describing the density-driven salt transport mechanism at the salt plug area with negative and positive estuarine circulation seaward and landward (respectively) from the salt plug area during the spring and neap tides. Inverse gravitational circulation between the salt plug and the coastal ocean caused outflows of high-salinity bottom water towards the coastal ocean from the salt plug area and inflows of relatively low-salinity surface water to the salt plug area from the ocean. In contrast, 
positive gravitational circulation between the salt plug and the river area drove high-salinity bottom water upstream. Thus, this result shows that $K$ also works in the direction opposite of the salt plug area, where gravitational circulation is reversed. In addition, our results demonstrated that $K$ not only varied spatially, but is also dependent on the river discharge level.

Salt water intrusion $\sim 96 \mathrm{~km}$ upstream from Chalna during the dry season, due to the negligible river discharge, indicates that salt water can also carry substances upstream that were introduced into the estuary by industries situated along the river. Moreover, if pollutants are introduced upstream, they may reside in the estuary until the next wet season, much to the detriment of the Pasur River estuarine ecosystem. Thus, our understanding of salt transport mechanisms may have far reaching implications and may contribute to a better understanding of the spatial and temporal distributions of pollutants, nutrients, and biota within large tropical estuaries.

Data availability. All datasets can be obtained by email from the first author (Dinesh Chandra Shaha, email: dinesh@bsmrau.edu.bd).

Competing interests. The authors declare that they have no conflict of interest.

Acknowledgements. This work was supported by the International Foundation for Science (IFS), Sweden (W/5414-1). Yang-Ki Cho was partly supported by the project entitled "Long-term change of structure and function in marine ecosystems of Korea", which was funded by the Ministry of Oceans and Fisheries, Korea. The first author would like to thank Md Shahidul Islam, La Trobe University, Australia, for his inspiring advice to write a research proposal for an IFS grant. The authors would like to thank Noim Imtiazy and Kowshik Pramanik for their support during the data collection process. We sincerely acknowledge and thank the Mongla Port Authority and all our field assistants for their constant support during the fieldwork. We also thank two anonymous reviewers who greatly improved this paper.

Edited by: Hubert H. G. Savenije

Reviewed by: two anonymous referees

\section{References}

Azevedo, I. C., Bordalo, A. A., and Duarte, P. M.: Influence of river discharge patterns on the hydrodynamics and potential contaminant dispersion in the Douro estuary (Portugal), Water Res., 44, 3133-3146, 2010.

BIWTA: Bangladesh Tide Tables 2014. BIWTA (Bangladesh Inland Water Transport Authority), Dhaka, Bangladesh, 128, 2014.
Dasgupta, S., Kamal, F. A., Khan, Z. H., Choudhury, S., and Nishat, A.: River salinity and climate change: evidence from coastal Bangladesh, World Bank Policy Research Working Paper, 2014.

Dyer, K. R.: Estuaries: a physical introduction, John Wiley, London, UK, 1997.

Eaton, T. T.: Analytical estimates of hydraulic parameters for an urbanized estuary - Flushing Bay, J. Hydrol., 347, 188-196, 2007.

Gain, A., Uddin, M., and Sana, P.: Impact of river salinity on fish diversity in the south-west coastal region of Bangladesh, Int. J. Ecol. Environ. Sci., 34, 49-54, 2008.

Gain, D., Sarower-E-Mahfuj, M., Sultana, S., and Mistri, N. A.: A preliminary study on fish fauna of the Passur River in Bangladesh, Int. J. Biodivers. Conserv., 7, 346-353, 2015.

Geyer, W. R.: The importance of suppression of turbulence by stratification on the estuarine turbidity maximum, Estuaries, 16, 113$125,1993$.

Gisen, J. I. A.: Prediction in ungauged estuaries, TU Delft, Delft University of Technology, 2015.

Hansen, D. V. and Rattray, M.: Gravitational circulation in straits and estuaries, J. Marine Res., 23, 104-122, 1965.

Intergovernmental Panel on Climate Change (IPCC): Climate change 2007: The physical science basis, Agenda, 6, 333, 2007.

Ippen, A. T. and Harleman, D. R.: One-dimensional analysis of salinity intrusion in estuaries, Corps of Engineers, US Army, Vicksburg, 1961.

Islam, S. N. and Gnauck, A.: Water shortage in the Gorai River Basin and Damage of mangrove wetland ecosystems in Sundarbans, Bangladesh, 1-14, 2011.

Khan, A. E., Ireson, A., Kovats, S., Mojumder, S. K., Khusru, A., Rahman, A., Vineis, P., and Labrese Ej, V.: Drinking water salinity and maternal health in coastal Bangladesh: implications of climate change, Environ. Health Persp., 119, 1328-1332, 2011.

Lee, J. and An, S.: Effect of dikes on the distribution and characteristics of Phragmites australis in temperate intertidal wetlands located in the South Sea of Korea, Ocean Sci. J., 50, 49-59, 2015.

McCarthy, R. K.: Residual currents in tidally dominated, wellmixed estuaries, Tellus A, 45, 325-340, 1993.

Mirza, M. M. Q.: Diversion of the Ganges water at Farakka and its effects on salinity in Bangladesh, Environ. Manage., 22, 711722, 1998.

Mirza, M. M. Q.: The Ganges water diversion: environmental effects and implications-an introduction, in: The Ganges water diversion: environmental effects and implications, Springer, 2004.

Rahaman, S. M., Biswas, S. K., Rahaman, M. S., Ghosh, A. K., Sarder, L., Siraj, S., and Islam, S. S.: Seasonal nutrient distribution in the Rupsha-Passur tidal river system of the Sundarbans mangrove forest, Bangladesh, Ecol. Process., 3, 1-11, https://doi.org/10.1186/s13717-014-0018-5, 2014.

Rahman, M. M., Hassan, M. Q., Islam, M. S., and Shamsad, S.: Environmental impact assessment on water quality deterioration caused by the decreased Ganges outflow and saline water intrusion in south-western Bangladesh, Environ. Geol., 40, 31-40, 2000.

Rahman, M. M., Rahman, T., Rahaman, M. S., Rahman, F., Ahmad, J. U., Shakera, B., and Halim, M. A.: Water quality of the world's largest mangrove forest, Can. Chem. Trans., 1, 141-156, 2013.

Rashid, H.: Geography of Bangladesh, The university press limited, Dhaka, Bangladesh, 1991. 
Samad, M., Mahmud, Y., Adhikary, R., Rahman, S., Haq, M., and Rashid, H.: Chemical Profile and Heavy Metal Concentration in Water and Freshwater Species of Rupsha River, Bangladesh, Am. J. Environ. Protect., 3, 180-186, 2015.

Savenije, H.: A one-dimensional model for salinity intrusion in alluvial estuaries, J. Hydrol., 85, 87-109, 1986.

Savenije, H.: Salinity and Tides in Alluvial Estuaries, completely revised 2nd Edn., 2012.

Savenije, H. H.: Predictive model for salt intrusion in estuaries, J. Hydrol., 148, 203-218, 1993.

Savenije, H. H.: Salinity and tides in alluvial estuaries, Elsevier, 2005.

Savenije, H. H.: Comment on "A note on salt intrusion in funnelshaped estuaries: Application to the Incomati estuary, Mozambique" by, Estuar. Coast. Shelf Sci., 68, 703-706, 2006.

Shaha, D. C. and Cho, Y.-K.: Determination of spatially varying Van der Burgh's coefficient from estuarine parameter to describe salt transport in an estuary, Hydrol. Earth Syst. Sci., 15, 1369-1377, https://doi.org/10.5194/hess-15-1369-2011, 2011.

Shaha, D. C. and Cho, Y. K.: Salt Plug Formation Caused by Decreased River Discharge in a Multi-channel Estuary, Scientific Reports, 6, 2016.

Shaha, D. C., Cho, Y.-K., Seo, G.-H., Kim, C.-S., and Jung, K. T.: Using flushing rate to investigate spring-neap and spatial variations of gravitational circulation and tidal exchanges in an estuary, Hydrol. Earth Syst. Sci., 14, 1465-1476, https://doi.org/10.5194/hess-14-1465-2010, 2010.
Stigter, C. and Siemons, J.: Calculation of longitudinal saltdistribution in estuaries as function of time, Waterloopkundig Laboratorium, 1967.

Uddin, M. and Haque, A.: Salinity response in southwest coastal region of Bangladesh due to hydraulic and hydrologic parameters, Int. J. Sustain. Agril. Tech, 6, 01-07, 2010.

Valle-Levinson, A.: Contemporary issues in estuarine physics, Cambridge University Press, 2010.

Valle-Levinson, A.: Classification of estuarine circulation, Treatise on estuarine and coastal science, 1, 75-86, 2011.

Van der Burgh, P.: Ontwikkeling van een methode voor het voorspellen van zoutverdelingen in estuaria, kanalen en zeeën, Rijkswaterstaat, Deltadienst, 1972.

Wahid, S. M., Babel, M. S., and Bhuiyan, A. R.: Hydrologic monitoring and analysis in the Sundarbans mangrove ecosystem, Bangladesh, J. Hydrol., 332, 381-395, 2007.

Wolanski, E.: An evaporation-driven salinity maximum zone in Australian tropical estuaries, Estuarine, Coast. Shelf Sci., 22, 415-424, 1986.

Zhang, Z. and Savenije, H. H. G.: The physics behind Van der Burgh's empirical equation, providing a new predictive equation for salinity intrusion in estuaries, Hydrol. Earth Syst. Sci., 21, 3287-3305, https://doi.org/10.5194/hess-21-3287-2017, 2017. 